\title{
Bioavailability links mode of action can improve the long-term field risk assessment for tilapia exposed to arsenic
}

\author{
Jeng-Wei Tsai ${ }^{\text {a }}$, Wei-Yu Chen ${ }^{\text {b }}$, Yun-Ru Ju ${ }^{\text {b }}$, Chung-Min Liao ${ }^{\text {b,* }}$ \\ a Institute of Ecology and Evolutionary Biology, China Medical University, Taichung, 40402, Taiwan, ROC \\ b Deaprtment of Bioenvironmental System Engineering, National Taiwan University, Taipei, 10617, Taiwan, ROC
}

\section{A R T I C L E I N F O}

\section{Article history:}

Received 24 July 2008

Accepted 28 January 2009

Available online 28 February 2009

\section{Keywords:}

Bioavailability

Arsenic

Tilapia

Mode of action

Biotic ligand model

Damage assessment model

\begin{abstract}
A B S T R A C T
The objective of this paper was to develop a mechanistic-based framework to explicitly incorporate the factors controlling the bioavailability, toxicodynamics and mode of action to enhance predictive ability of arsenic (As) toxicity to protect the health of farmed tilapia Oreochromis mossambicus. We linked the biotic ligand model and damage assessment model to develop a toxicokinetic model for elucidating the site-specific temporal changes of As bioavailability and to characterize how the fish regulate the metal toxicity. We built a bioavailability-mode of action-based growth toxicity model by linking a bioenergetic growth model and damage assessment model to predict how the As affects on the tilapia growth in the entire life span in sitespecific field ecosystems. Here we show that the proposed model well describes the water-chemistrydependent toxicokinetics and toxicodynamics variations of As to tilapia. We selected two local tilapia farms with different water chemistries located at southwestern Taiwan coast region to implement the proposed algorithm to predict the risk of As exposure. Results indicate that the growth toxicity of 0 . mossambicus in Taihsi is more sensitive than that in Peimen. We found that the effect of ion competition on the As bioavailability and their ecotoxicological effects on tilapia are more obvious in Taihsi comparing with that in Peimen. We suggested that the proposed bioavailability- and mode of action-based framework can be used to capture the biological response and regulation of tilapia to As exposures. It is applicable for a site-specific and long-term ecotoxicological risk assessment.
\end{abstract}

(c) 2009 Elsevier Ltd. All rights reserved.

\section{Introduction}

The major challenge of predicting the potential risk of heavy metal to aquatic organism in field ecosystem is to reflect the changes of chemical bioavailability in different sites and to consider the biology regulation of biota during long term exposures. Traditionally, toxicokinetic and toxicodynamic models treat the bioconcentration factor as constant and are independent of water chemistry. In recent years, the biotic ligand model (BLM) has been intensively developed to implicitly account for the effect of water chemistry on the metal bioavailability to organisms. The application of BLM improves the prediction of the safe environmental concentrations of a metal as a function of site-specific key water characteristics. Site-specific water chemistries affect the metal bioavailability and toxicity by considering both metal speciation (affected by $\mathrm{pH}$, formation of organic and inorganic complexes) and competition between the major cations and the metal for binding to the site of action (i.e., the gills of aquatic organism) on to the organism. The BLM was initially developed for predicting the acute metal toxicity. Recently BLM had been demon-

\footnotetext{
* Corresponding author. Tel.: +8862 2363 4512; fax: +8862 23626433. E-mail address: cmliao@ntu.edu.tw (C.-M. Liao).
}

strated to accurately predict the acute and chronic effect concentration for $50 \%$ response even more the no observed effect concentration and lowest observed effect concentration by assuming that there are no changes in the process between chronic and acute toxicity (Heijerick et al., 2005). The BLM, however, is still limited to elucidate the inherent toxicity mechanisms between chronic and acute toxicity.

To reveal how the metal toxicity exerts to aquatic organism, the damage assessment model (DAM) (Lee et al., 2002) had been developed to quantitatively depict the time course of toxicity, inherent interactions between chemicals and receptors and internal regulations of organisms. The DAM describes the mode of action of compounds with rapid reversible binding to the target site as well as to those that act with irreversible binding (Lee et al., 2002). The DAM model provides a more comprehensive framework to investigate the time-dependent toxicity of chemical incorporating the co-influence of chemical accumulation and damage accumulation. This is particularly true for real field exposures.

A bioenergetics-based framework is developed (Tsai and Liao, 2006b) for assessing the potential whole-life-span growth toxicity of arsenic (As) to tilapia under different exposure scenarios. This ontogenetic growth toxicity model is constructed by incorporating the well-known dynamic energy budget $\left(\mathrm{DEB}_{\text {tox }}\right)$ theory (Kooijman and Bedaux, 1996) with a universal West growth model (West et al., 2001). The conventional analysis of bioassays does not account for 
biological significance for chemical effects. The $\mathrm{DEB}_{\text {tox }}$ theory well describes the relationships between energy assimilation of organisms and energy utilization priority between basal metabolism, growth and reproduction under stresses (Nisbet et al., 2000). The West growth model provides the basis for deriving allometric relationships for growth rate and the timing of life history events and has been applied successfully to predict the growth of many diverse species elsewhere (West and Brown, 2004). However, neither the DAM nor our previous developed ontogenetic growth toxicity model does account for the effects of water chemistry on metal bioavailability for organism which lead to the limitation of these models in field applications.

Long-term diet exposure of ingesting inorganic arsenic in artesian well water has been demonstrated to induce blackfoot disease, a unique peripheral vascular disease that ends with dry gangrene and spontaneous amputation of affected extremities in southwestern coastal area of Taiwan (Chen et al., 2001). Nowadays, the local residents do not drink the well water. However, artesian well water is still used for aquaculture. Farming tilapia (Oreochromis mossambicus) is one of the promising practices in the southwestern coastal area of Taiwan because of its high market value. The As concentration in blackfoot disease area pond water showed wide spatial varieties and ranging from 8.1 to $251.7 \mu \mathrm{g} \mathrm{L}^{-1}$ (Singh, 2001; Liao et al., 2003). Arsenic contents in several farming ponds even exceed the water quality criteria for total As in the freshwater ecosystems ( $\left.150 \mu \mathrm{g} \mathrm{L}^{-1}\right)$ documented by the Criterion Continuous Concentration (USEPA, 2002). If As levels in pond water raise high, severe effects may pose risk to the health of farmed fish and consequently increase the expenditure of farmers. Furthermore, the consumption of farmed tilapia from blackfoot disease area may also pose a potential risk to human health.

It is definitely that a comprehensive ecological risk assessment framework is supposed to link the bioavailability, toxicokinetics, mode of action and toxicodynamics knowledge to elucidate a more reliable result for chronic exposure risk assessment, especially to reflect the site-specific water chemistries. The purposes of this study are (1) to develop a toxicokinetic model for elucidating the temporal changes of the bioavailability of As (i.e., the bioconcentration factor) under different water chemistry compositions, (2) to develop a mechanisticbased framework to elucidate the how the fish biologically react to the

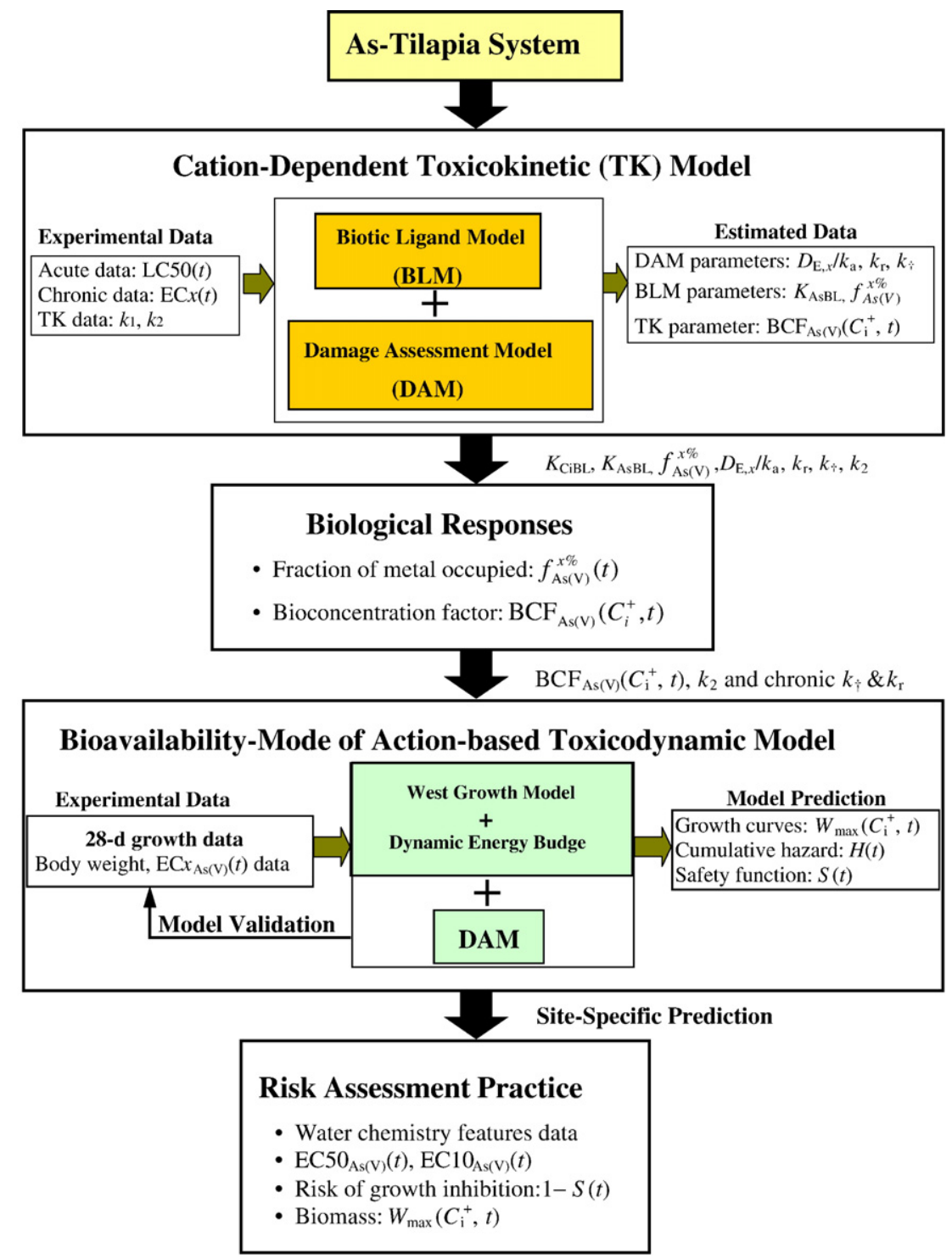

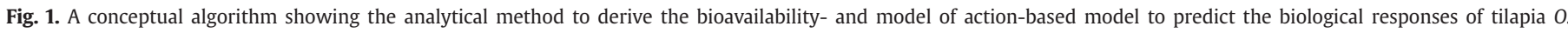

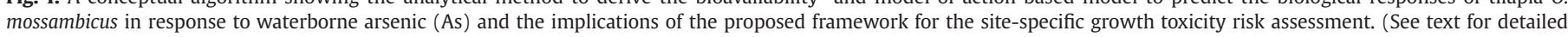
descriptions of symbol.) 
chemical stress, and (3) to predict how the As affects on the tilapia growth in the entire life span in site-specific field ecosystems.

\section{Materials and methods}

\subsection{Mechanistic models}

The BLM quantifies the affinity and capacity of the biotic ligand in gill of aquatic organisms to bind metals, relating this binding to the magnitude of toxic effect under various water chemistry settings. The basic hypothesis of the BLM is that the degree of toxic effect is determined by the fraction bound to the site of action (i.e., biotic ligand). The relationship between the observed effect and the fraction of occupied biotic ligand is not altered by the physicochemistry of the bulk water (Pagenkopf, 1983; Meyer et al., 1999; Heijerick et al., 2002). This suggests that the fraction of the biotic ligand sites occupied by metal ions $\left(\mathrm{M}^{+}\right)$, the $f_{\mathrm{MBL}}$, is constant and is independent of water characteristics of test medium. The effect concentration for $x \%$ response shown in free metal ion concentration $\left(\mathrm{EC}_{\mathrm{M}^{+}}\right)$represents the effective external chemical concentration needed to occupy the biotic ligand in a fixed toxic effect. Fig. 1 illustrates the computational algorithm of this study.

\subsubsection{Develop a water chemistry-based toxicokinetic model}

The first step of this study is to develop a toxicokinetic model. At equilibrium thermodynamics, $\mathrm{As}(\mathrm{V})$ dominates in oxidative environments of most surface waters. As(V) thus is the most prevalent in most surface waters (Fergusion and Gavis, 1972). We linked the BLM and the DAM to elucidate the time series of $f_{\mathrm{MBL}}$ and to predict the temporal changes of bioconcentration factor considering the competitive effects of cations. We proposed that the active concentration for $x \%$ effect at selected time $(t)$ calculated by the DAM $\left(\operatorname{EC} x_{\operatorname{DAm}, A s(V)}(t)\right)$ (Lee et al., 2002 ) equals to the $\mathrm{EC} x_{\mathrm{As}(\mathrm{V})}$ predicted by the BLM (Heijerick et al., 2002),

$$
\frac{D_{\mathrm{E}, x} / k_{\mathrm{a}}}{\left(\frac{e^{-k_{\mathrm{r} t} t}-e^{-k_{2} t}}{k_{\mathrm{r}}-k_{2}}+\frac{1-e^{-k_{\mathrm{r}} t}}{k_{\mathrm{r}}}\right)} \mathrm{BCF}_{\mathrm{As}(\mathrm{V})}^{-1}\left(C_{i}^{+}, t\right)=\frac{f_{\mathrm{As}(\mathrm{V})}^{x^{\circ}}(t) \times\left[1+\sum_{i} K_{C_{\mathrm{B}} \mathrm{BL}}\left(C_{i}^{+}\right)\right]}{\left(1-f_{\mathrm{As}(\mathrm{V})}^{x^{x / \%}}(t)\right) \times K_{\mathrm{AsBL}}},
$$

where $D_{\mathrm{E}, x}$ is the accumulated tissue damage accounting for $x$ effect (\%), $k_{\mathrm{a}}$ is the damage accumulation rate $\left(\mathrm{g} \mathrm{\mu g}^{-1} \mathrm{~d}^{-1}\right), k_{\mathrm{r}}$ is the damage recovery rate constant $\left(\mathrm{d}^{-1}\right), D_{\mathrm{E}, x} / k_{\mathrm{a}}$ is a coefficient that reflects the compound equivalent toxic damage level required for $x \%$ effect $\left(\mu g \mathrm{dg}^{-1}\right), \mathrm{BCF}_{\mathrm{As}(\mathrm{V})}$ $\left(C_{i}^{+}, t\right)$ is the bioconcentration factor of $\mathrm{As}(\mathrm{V})$ to organism considering the competition of cations $C_{i}^{+}$at time $t, f_{\mathrm{As}(\mathrm{V})}^{x \%}(t)$ is the response timedependent fraction of the total number of gill binding sites occupied by $\mathrm{As}(\mathrm{V})$ at $x \%$ effect. $K_{\mathrm{C}_{\mathrm{B}} \mathrm{BL}}$ is stability constant for the binding of the cation to the biotic ligand $\left(\mathrm{M}^{-1}\right)$ affecting $\mathrm{As}(\mathrm{V})$ toxicity, $K_{\mathrm{AsBL}}$ is stability constant of $\mathrm{As}(\mathrm{V})$ at the biotic ligand, $C_{i}^{+}$is activity of the cation affecting $\mathrm{As}(\mathrm{V})$ toxicity. $D_{\mathrm{E}, x} / k_{\mathrm{a}}$ and $k_{\mathrm{r}}$ in Eq. (1) can be estimated by fitting the $\mathrm{EC} x_{\mathrm{DAm}, \mathrm{As}(\mathrm{V})}(t)$ to time-dependent $x \%$ lethal concentration $(\operatorname{LC} x(t))$ data, whereas $k_{2}$ is derived by fitting the one-compartment bioaccumulation model to the bioaccumulation curves.

The BLM assumes that $f_{\mathrm{As}(\mathrm{V})}^{x \%}(t)$ is independent of water chemistry. Thus fish are exposed in the deionic solution. We thus rearranged the Eq. (1) to obtain a mechanistic model to predict the temporal changes of bioconcentration factor as,

$$
\mathrm{BCF}_{\mathrm{As}(\mathrm{V})}\left(C_{i}^{+}, t\right)=\frac{\left\lfloor 1-f_{\mathrm{As}(\mathrm{V})}^{\chi \%}(t)\right\rfloor \times K_{\mathrm{AsBL}} \times\left(D_{\mathrm{E}, x} / k_{\mathrm{a}}\right) \times k_{\mathrm{r}}}{f_{\mathrm{As}(\mathrm{V})}^{\chi \%}(t) \times\left[1+\sum_{i} K_{C_{i} \mathrm{BL}}\left(C_{i}^{+}\right)\right]} .
$$

We quantitatively linked the relationship between $\mathrm{BCF}_{\mathrm{As}(\mathrm{V})}\left(C_{i}^{+}, t\right)$ and $f_{\mathrm{As}(\mathrm{V})}^{\chi}{ }^{\%}(t)$ at steady-state with Eq. (2). Therefore, the traditional one-compartmental toxicokinetic model is refined with the concept of ion competition.

\subsubsection{Biological responses of tilapia to As}

The DAM describes the time-dependent toxicity by linking the process of chemical accumulation and tissue damage in organisms instead of merely depending on the chemical dose in the target site. These are advocated by the critical body residue model (McCarty and Mackay, 1993) and the critical area under the curves model (Legierse et al., 1999). To obtain the time series of $f_{\mathrm{As}(\mathrm{V})}^{x \%}(t)$ for assessing the biological response of tilapia, we substitute the $f_{\mathrm{As}(\mathrm{V})}^{X \%}(t)$ into BLM with an exponential equation (Liao et al., 2007) as

$$
\mathrm{EC} x_{\mathrm{As}(\mathrm{V})}(t)=\frac{[c+d \exp (-t / e)] \times\left\{1+\sum_{i} K_{C_{i} \mathrm{BL}}\left(C_{i}^{+}\right)\right\}}{\{1-[c+d \exp (-t / e)]\} \times K_{\mathrm{AsBL}}},
$$

where $c, d$, and $e$ are fitting coefficients. $K_{\mathrm{AsBL}}$ accounts for the effect concentration for 50\% lethality (LC50) and effect concentration for 50\% (EC50) and for 10\% response (EC10) (the endpoint is growth inhibition). LC50, EC50, and EC10 can be estimated by optimal fitting Eq. (3) to free $\mathrm{As}(\mathrm{V})$ concentration for $50 \%$ lethality at time $t\left(\mathrm{LC} 50_{\mathrm{As}(\mathrm{V})}(t)\right)$, free $\mathrm{As}(\mathrm{V})$ concentration for $50 \%$ effect $\left(\mathrm{EC} 0_{\mathrm{As}(\mathrm{V})}(t)\right)$ and for $10 \%$ effect $\left(\mathrm{EC} 10_{\mathrm{As}(\mathrm{V})}\right.$ $(t)$ ) data obtained from our previous experiment-derived LC50 $(t)$ data (Tsai and Liao, 2006a) and EC50(t) and EC10(t) data (Tsai and Liao, 2006b).

\subsubsection{Develop a toxicodynamics model for site-specific risk assessment}

Our previous study (Tsai and Liao, 2006b) reveals that the mode of action and growth toxicity of As to tilapia was exerted by reducing the food assimilation efficiency. This can be well predicted by a bioenergetical-based feeding decrease model as

$W(t)=W_{\max }\left\{1-\left[1-\left(\frac{0.05}{W_{\max }}\right)^{1 / 4}\right] e^{-a t / 4 W_{\max }^{1 / 4}}\right\}^{4}$,

where $a$ is a species-specific growth coefficient $\left(\mathrm{g}^{1 / 4} \mathrm{~d}^{-1}\right), W(t)$ is the time-dependent body weight, 0.05 is the body weight at birth $(\mathrm{g}), W_{\max }$ is the ultimate body weight $(\mathrm{g})$ of contaminated tilapia related to chemical stress as $W_{\max }=W_{\max } \times S(t)$ where $W_{\max 0}$ is the maximum body weight $(\mathrm{g})$ of tilapia in uncontaminated water, $S(t)$ is a safety function that related the health of organism to body residues and cumulative damage as $S(t)=\mathrm{e}^{-H(t)}$ where $H(t)$ is the cumulative hazard (dimensionless) which can be linked to tissue damage as $H(t)=k_{3} \times D$ $(t)$ where $k_{3}$ is a proportionality constant (dimensionless), $D(t)$ is referred to as the time-dependent cumulative damage (dimensionless) and can be estimated from the solution of first-order damage accumulation model, $\mathrm{d} D(t) / \mathrm{d} t=k_{\mathrm{a}} C_{\mathrm{wb}}(t)-k_{\mathrm{r}} D(t)$ where $C_{\mathrm{wb}}(t)$ is the internal chemical residue. This leads to the following expression for $S(t)$ as (Lee et al., 2002)

$S(t)=e^{-\left[k_{3} k_{\mathrm{a}} \mathrm{BCF}(t) C_{\mathrm{w}}\left(\frac{e^{-k_{\mathrm{r}} t}-e^{-k_{2} t}}{k_{\mathrm{r}}-k_{2}}+\frac{1-e^{-k_{\mathrm{r}} t}}{k_{\mathrm{r}}}\right)\right]}$

Kooijman and Bedaux (1996) introduced a constant, called killing rate $\left(k_{\uparrow}\right)$, to represent a measure for the toxicity of a compound and

\section{Table 1}

Distributions and point values of affinity constants $\left(\log K, \mathrm{M}^{-1}\right)$ of biotic ligand-cation complexes used in the presented BLM- and DAM-based toxicokinetic and toxicodynamic model.

\begin{tabular}{lll}
\hline Affinity constants $\left(\mathrm{M}^{-1}\right)$ & Acute toxicity & Chronic toxicity $^{\mathrm{a}}$ \\
\hline $\log K_{\mathrm{MgBL}}$ & $3.58^{\mathrm{b}}$ & $\mathrm{LN}(2.88,1.11)$ \\
$\log K_{\mathrm{HBL}}$ & $5.40^{\mathrm{b}}$ & $\mathrm{LN}(6.36,1.06)$ \\
$\log K_{\mathrm{CaBL}}$ & $\mathrm{LN}(3.53,1.03)^{\mathrm{c}}$ & $\mathrm{LN}(3.40,1.08)$ \\
$\log K_{\mathrm{NaBL}}$ & $\mathrm{LN}(3.09,1.04)^{\mathrm{c}}$ & $\mathrm{LN}(2.57,1.17)$ \\
\hline
\end{tabular}

a Adopted from Chen et al. (in press).

b Adopted from Niyogi and Wood (2004).

c Adopted from Liao et al. (2007) in that LN(gm, gsd) represents lognormal distribution with a geometric mean and a geometric standard deviation. 
Table 2

Input parameters and parameter estimations for the presented model fitted to the $\mathrm{LC} 50_{\mathrm{As}(\mathrm{V})}(t), \mathrm{EC} 0_{\mathrm{As}(\mathrm{V})}(t)$ and $\mathrm{EC} 10_{\mathrm{As}(\mathrm{V})}(t)$ of the arsenic-tilapia system.

\begin{tabular}{lll}
\hline & Acute toxicity $^{\mathrm{a}}$ & Chronic toxicity $^{\mathrm{b}}$ \\
\hline Input parameter $^{\mathrm{c}}$ & & \\
$k_{1}\left(\mathrm{~mL} \mathrm{~g}^{-1} \mathrm{~d}^{-1}\right)$ & $0.31 \pm 0.086$ & $0.31 \pm 0.086$ \\
$k_{2}\left(\mathrm{~d}^{-1}\right)$ & $0.028 \pm 0.11$ & $0.028 \pm 0.11$ \\
$\mathrm{BCF}\left(\mathrm{mL} \mathrm{g}^{-1}\right)$ & 2.44 & 2.44 \\
& & \\
Parameter estimates & $3.86 \pm 0.53^{\mathrm{d}}$ & $1.61 \pm 0.71^{\mathrm{e}}\left(0.74 \pm 0.30^{\mathrm{f}}\right)$ \\
$D_{\mathrm{L}, 50} / k_{\mathrm{a}}\left(\mathrm{pmol} \mathrm{d} \mathrm{g}^{-1}\right)$ & $4.05 \pm 0.75^{\mathrm{d}}$ & $0.70 \pm 0.33^{\mathrm{e}}\left(0.72 \pm 0.31^{\mathrm{f}}\right)$ \\
$k_{\mathrm{r}}\left(\mathrm{d}^{-1}\right)$ & $0.18^{\mathrm{d}}$ & $0.43^{\mathrm{e}}\left(0.14^{\mathrm{f}}\right)$ \\
$k_{\dagger}\left(\mathrm{g} \mathrm{pmol}^{-1} \mathrm{~d}^{-1}\right)$ & $0.30^{\mathrm{d}}$ & $0.23^{\mathrm{e}}$ \\
$f_{\mathrm{As}(\mathrm{V})}^{50 \%}(\infty)$ &
\end{tabular}

a The observed endpoint of acute bioassay is mortality.

b The observed endpoint of chronic bioassay is growth inhibition.

c Adopted from Liao et al. (2004).

d Parameters estimated from $\mathrm{LC50}_{\mathrm{As}(\mathrm{V})}(t)$ data adopted from Tsai and Liao (2006a).

e Parameters estimated from $\mathrm{EC} \mathrm{As}_{\mathrm{As}(\mathrm{V})}(t)$ data adopted from Tsai and Liao (2006b).

f Parameters estimated from $\mathrm{EC} 10_{\mathrm{As}(\mathrm{V})}(t)$ data adopted from Tsai and Liao (2006b).

has the dimension [(tissue concentration $\times$ time $)^{-1}$ ] in that $k_{\dagger}=k_{3} k_{\mathrm{a}}$. The killing rate is the proportionality factor that describes the relation between the accumulated hazard and the cumulative damage. In the case of $50 \%$ and $10 \%$ effects, $k_{\dagger}$ values are calculated as $\ln 2 /\left(D_{\mathrm{E}, 50} / k_{\mathrm{a}}\right)$ and $\ln 0.9 /\left(D_{\mathrm{E}, 10} / k_{\mathrm{a}}\right)$, respectively, followed the algorithm of Lee et al. (2002). The BCF $(t)$ in Eq. (5) could be substituted by Eq. (2) to account for the site-specific water chemistry settings.

\subsection{Model parameterization and validation}

Niyogi and Wood (2004) summarized the estimated stability (or affinity) constant ( $\log K$ ) of cation-BL and inorganic complexes used in BLM developed for fathead minnow P. promelas and D. magna, respectively. We optimally fitted the lognormal distributions for $\log \mathrm{Ks}$ (Table 1). The input parameters, including toxicokinetic parameters (i.e., $k_{1}, k_{2}$, and $\mathrm{BCF}_{\mathrm{As}(\mathrm{V})}(t)$ of fish gill) and toxicodynamic parameters (i.e., $D_{\mathrm{E}, x} / k_{\mathrm{a}}$ and $k_{\mathrm{r}}$ ) can be adopted and estimated from Liao et al. (2004) and Tsai et al. (2006), respectively (Table 2).
Tsai and Liao (2006b) conducted chronic As bioassays to obtain the time series of tilapia growth curves. We reanalyzed these data and used them to validate the proposed growth toxicity model by using root-meansquared-error (RMSE), computed from RMSE $=\sqrt{\sum_{n=1}^{N}\left(C_{\mathrm{m}, n}-C_{\mathrm{s}, n}\right)^{2} / N}$ where $N$ denotes the number of measurements, $C_{\mathrm{m}, n}$ is the measurement data, and $C_{\mathrm{s}, n}$ is the simulation result corresponding to data point $n$. The essential bioenergetic parameters (i.e., $a$ and $W_{\max }$ ) of the West growth model for tilapia are also adopted from Tsai and Liao (2006b) and the database of FishBase (http://www.fishbase.org/search.php).

We used Statistica ${ }^{\circledR}$ software (StatSoft, Tulsa, OK, USA) to optimally fit the published data to obtain the optimal statistical models to perform all curve fittings in this study. The Statistica ${ }^{\circledR}$ is also used to calculate the coefficient of determination $\left(r^{2}\right)$. Statistical significance is judged when $p$ values are less than 0.05 . We performed WHAM (Windermere humic aqueous model) Version 6 (WHAM VI, Center for Ecology and Hydrology, Lancaster, UK) to calculate the activities of the competing cations considered in this study. The default inorganic arsenic form in WHAM is arsenate $\left(\mathrm{AsO}_{4}\right)$ with site-specific water chemistry, varied temperature and $\mathrm{pH}$ value. We employed the Crystal Ball $^{\circledR}$ software (Version 2000.2, Decisioneering, Inc, Denver, Colorado, USA) to implement the Monte Carlo simulation to obtain 2.5th- and 97.5th-percentiles as the $95 \%$ confidence interval (CI).

\section{Results}

\subsection{Bioaccumulation and biological response of tilapia}

Acute and chronic toxicity data (i.e., $\mathrm{LC} 0_{\mathrm{As}(\mathrm{V})}(t), \mathrm{EC} 0_{\mathrm{As}(\mathrm{V})}(t)$, and $\left.\mathrm{EC} 10_{\mathrm{As}(\mathrm{V})}(t)\right)$ are derived by transforming the original published data into ion activity unit with the WHAM software at a specific water temperature $28^{\circ} \mathrm{C}$ and a pH value of 7.8 . The temporal changes of the response time-dependent fraction of the total number of gill binding sites occupied by As $(\mathrm{V})$ at $50 \%$ effect $\left(f_{\mathrm{As}}^{50 \%}(\mathrm{~V})(t)\right)$ reveals how the fish regulate the chemical toxicity and their physiological changes with the extension of exposure time. We estimated $f_{\mathrm{As}(\mathrm{V})}^{50 \%}(t)$ by fitted Eq. (3) to published $\operatorname{EC50}(t)$ and $\operatorname{LC50}(t)$ data (Tsai and Liao, 2006a,b) associated with known ionic composition and the estimated stability constant $\log K$ values shown in Table 1 Fig. $2 \mathrm{~A}$ and $\mathrm{B}$ shows a comparison between measured and predicted $\mathrm{LC}_{\mathrm{C}} \mathrm{As}_{\mathrm{AV})}(t)\left(r^{2}=0.85\right)$ and $\mathrm{EC} 0_{\mathrm{As}(\mathrm{V})}(t)\left(r^{2}=0.76\right)$, respectively, indicating measured data all fall within the $95 \% \mathrm{Cl}$ ranges. The $K_{\mathrm{AsBL}}$ and $1+\sum K_{C_{\mathrm{i}} \mathrm{BL}}\left(C_{i}\right)$ were estimated to be $2.45 \times 10^{7} \mathrm{M}^{-1}$ and 1.004 and $5.19 \times 10^{8} \mathrm{M}^{-1}$ and 1.037 in acute and chronic schemes, respectively.

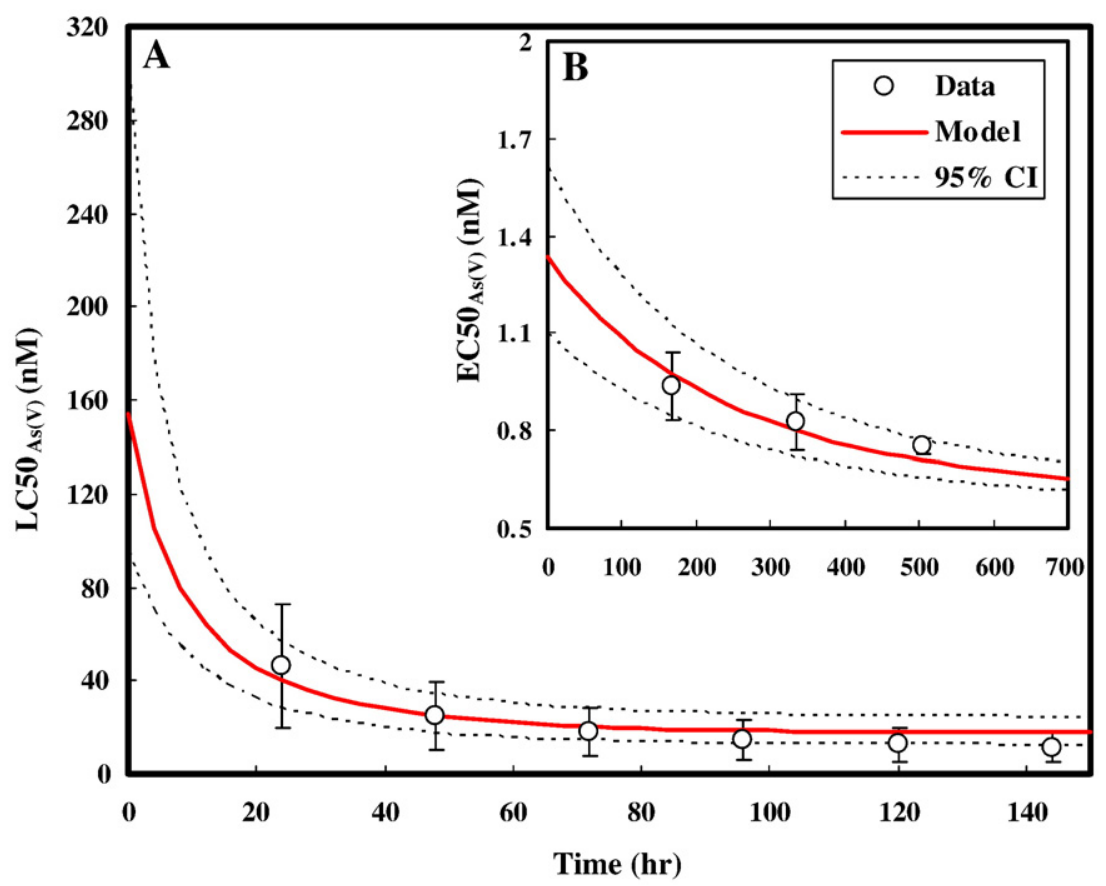

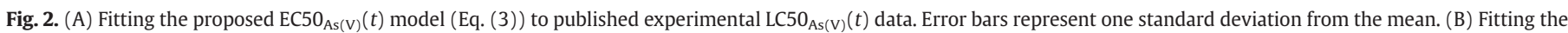
proposed $\mathrm{EC} \mathrm{As}_{\mathrm{Av}(\mathrm{V})}(t)$ model (Eq. (3)) to published experimental $\mathrm{EC} 50_{\mathrm{As}(\mathrm{V})}(t)$ data. Error bars represent one standard deviation from the mean. 

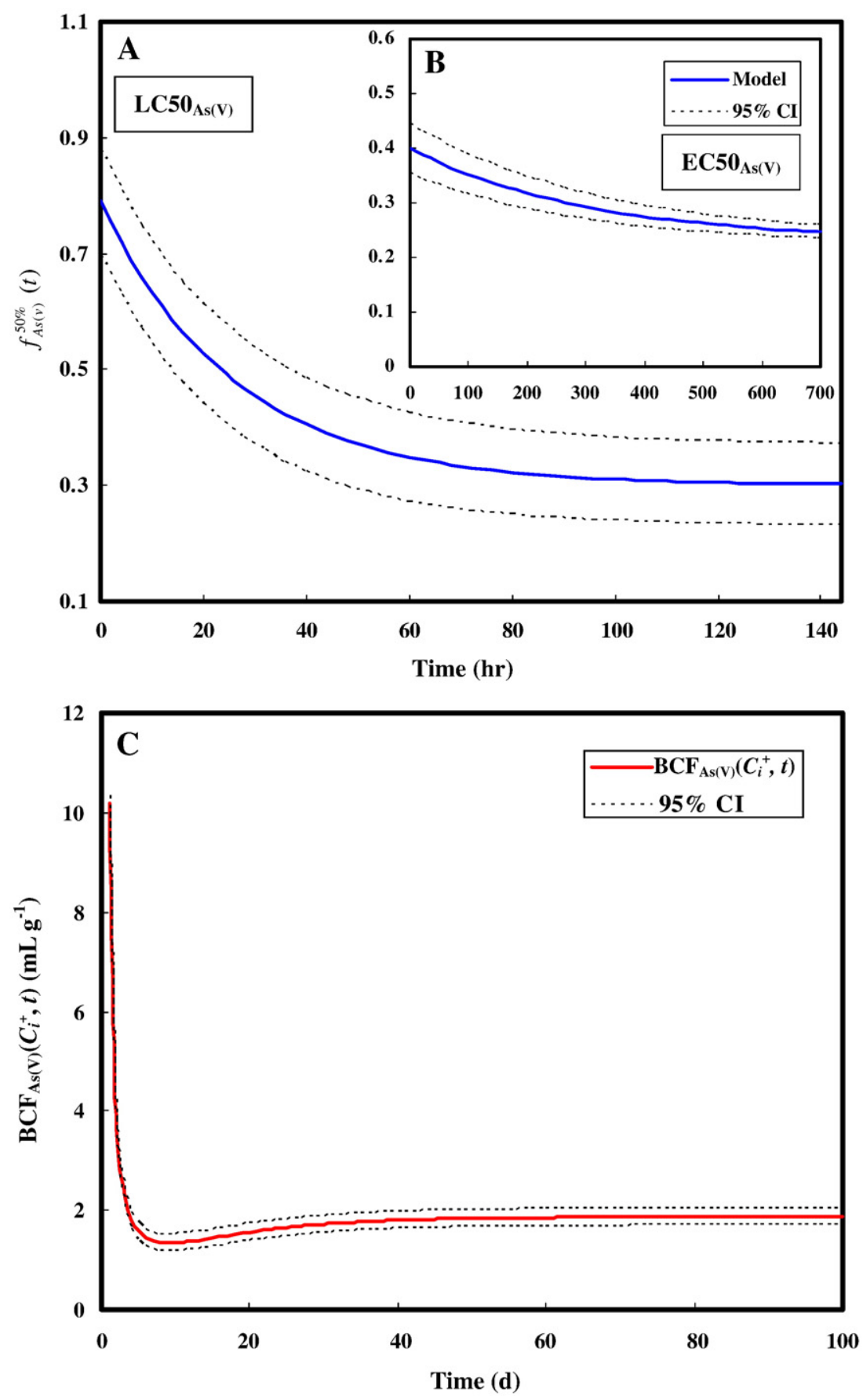

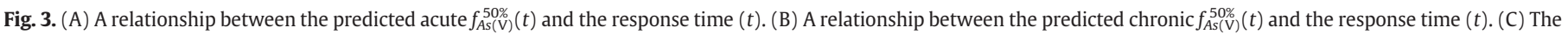
time series of bioaccumulation factor (i.e., $\mathrm{BCF}_{\mathrm{As}(\mathrm{V})}\left(C_{i}^{+}, t\right)$ predicted by Eq. (2).

Fig. $3 \mathrm{~A}$ and B illustrates the temporal trend of estimated $f_{\mathrm{As}(\mathrm{V})}^{50 \%}(t)$ in acute and chronic exposure scenarios, respectively. The fitted acute $f_{\mathrm{As}(\mathrm{V})}^{50 \%}(t)$ had the form $f_{\mathrm{As}(\mathrm{V})}^{5 \%}(t)=0.3+$ $0.49 \times \exp (-t / 26)\left(r^{2}=0.85\right)$ and the chronic $f_{\mathrm{As}(\mathrm{V})}^{50 \%}(t)=0.23+0.17 \times \exp (-t / 300)$ $\left(r^{2}=0.76\right)$, respectively. Both predictions show that the $f_{\mathrm{As}(\mathrm{V})}^{50 \%}(t)$ curves exponentially decrease as the exposure time extended, revealing the regulating of metal toxicity at the target sites. The acute $f_{\mathrm{As}(\mathrm{V})}^{50 \%}(t)$ decrease from 0.79 at $t=0 \mathrm{~h}$ to 0.38 at $t=144 \mathrm{~h}$, whereas the chronic $f_{\mathrm{As}(\mathrm{V})}^{50 \%}(t)$ decrease from 0.41 at $t=0 \mathrm{~h}$ to 0.26 at $t=700 \mathrm{~h}$. These indicate that the required $f_{\mathrm{As}(\mathrm{V})}^{50 \%}(t)$ value in inducing acute death is larger than these for chronic growth inhibition.

Fig. 3C illustrates the temporal change of $\mathrm{BCF}_{\mathrm{As}(\mathrm{V})}\left(C_{i}^{+}, t\right)$, which is predicted by Eq. (3) with the input of chronic DAM parameters (i.e., $D_{\mathrm{E}, 50} / k_{\mathrm{a}}$ and $k_{\mathrm{r}}$ ), BLM parameters (i.e., $K_{\mathrm{AsBL}}$ and $\left.K_{\mathrm{CiBL}}\right)$ and the predicted chronic $f_{\mathrm{As}(\mathrm{V})}^{50 \%}(t)$. The predicted $\mathrm{BCF}_{\mathrm{As}(\mathrm{V})}\left(C_{i}^{+}, t\right)$ shows dramatic decreasing from about $10.2 \mathrm{~mL} \mathrm{~g}^{-1}$ initially and then slowly increase to a steadystate value of $1.87 \mathrm{~mL} \mathrm{~g}^{-1}$ (Fig. 3C), revealing that the potential biologically regulation of organisms when they are exposed to chemicals especially in the first few days of exposures.
The quantitative relationship between $\mathrm{BCF}_{\mathrm{As}(\mathrm{V})}\left(C_{i}^{+}, t\right)$ and $f_{\mathrm{As}(\mathrm{V})}^{50 \%}(t)$ in steady-state (i.e., $t=\infty$ ) could be established by Eq. (2) with an uncertainty analysis of the two parameters. The $f_{\mathrm{As}(\mathrm{V})}^{50 \%}(t)$ and $\mathrm{BCF}_{\mathrm{As}(\mathrm{V})}\left(C_{i}^{+}, \infty\right)$ are 0.23 (95\%CI: 0.224-0.236) and 1.87 (95\%CI: 0.70-4.03), respectively (Fig. 4). Result indicates that the $\mathrm{BCF}_{\mathrm{As}(\mathrm{V})}\left(C_{i}^{+}, \infty\right)$ negatively correlates with the $f_{\mathrm{As}(\mathrm{V})}^{x \%}(\infty)$, revealing that the organism with higher $f_{\mathrm{As}(\mathrm{V})}^{50 \%}(\infty)$ has lower ability to accumulate the bioavailable chemicals. Fig. $4 \mathrm{~B}$ illustrates a response surface best described by a fitted model of $f_{\mathrm{As}(\mathrm{V})}^{x \%}\left(x, t_{\mathrm{R}}\right)=0.083+0.003 x+0.161 \times \exp \left(-t_{\mathrm{R}} / 332\right)$, reflecting a $f_{\mathrm{As}(\mathrm{V})}^{x}{ }^{\%}(t)-$ response time-response interaction.

\subsection{Validation and risk assessment applications}

Fig. 5 shows the optimal fits of the growth toxicity model to the previous bioassay data (Tsai and Liao, 2006b). The concentration-specific RMSE values for the model performances range from 0.045 to 0.221 and all of them are within the error limits (ranging from 0.83 to 1.60 ) of the experimental data, indicating that the proposed 


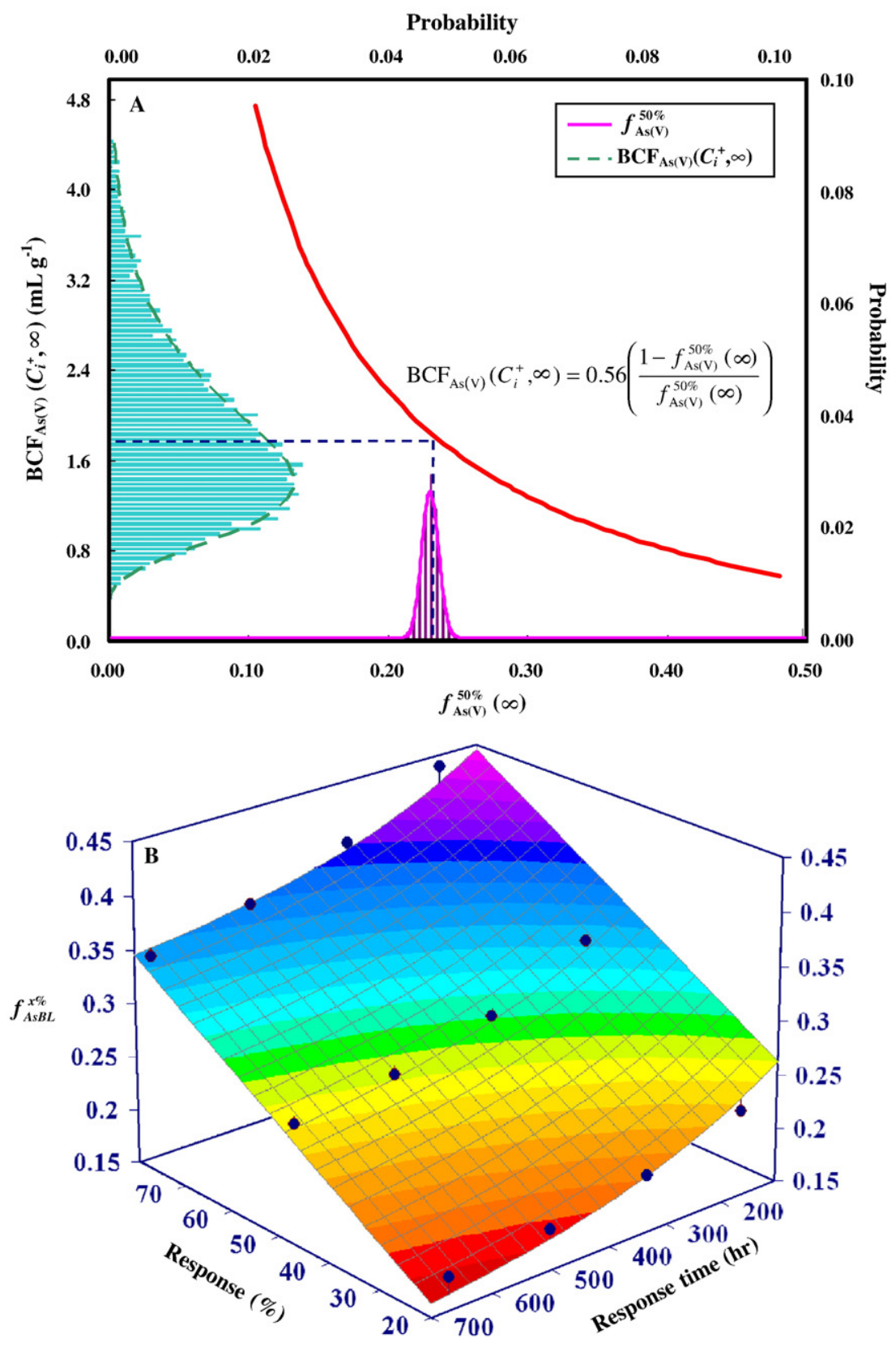

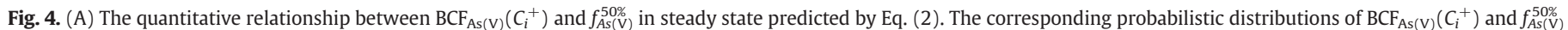
are shown in $Y$ and $X$ axis, respectively. (B) A response surface showing the relationship among $f_{A s(V)}^{x \%}$, response time, and response.

growth model is capable of describing the effect of growth of tilapia by As under various chronic exposure scenarios.

Here we selected water characteristics of two local tilapia farms located at Taihsi and Peimen in the southwestern Taiwan region associated with toxicokinetic and toxicodynamic data to implement the proposed model to predict the risk of metal exposure. We designated fish farm located in these two towns due to the obvious difference in their water chemistry compositions. Peimen is one of the major areas for producing salt in Taiwan, salinization factor obviously affects the dynamics of ion content (i.e., $\mathrm{Ca}^{2+}, \mathrm{Mg}^{2+}, \mathrm{Na}^{+}, \mathrm{K}^{+}, \mathrm{Cl}^{-}$and $\mathrm{SO}_{4}^{2-}$ ) in groundwater (Wang et al., 2007). Hence the water chemistries of pond water are much affected by salinity than those in Taihsi. Thus we adopted them as references to test the proposed models and to estimate the exposure risk of fish under different scenarios in these two sites. Distributions of measured metal ion concentrations were fitted to the polled field observations obtained from tilapia farms (Table 3). The lognormal distribution model best fits the observed data of ion activity concentrations in two selected favorably. All variables modeled as the lognormal distributions from which geometric mean and geometric standard deviation for each variable were calculated.

We performed Eq. (3) with inputs of $f_{\mathrm{As}(\mathrm{V})}^{50 \%}(t)$ (Fig. 3B) and $f_{\mathrm{As}(\mathrm{V})}^{10 \%}(t)$ and site-specific water chemistry settings (Table 3 ) to predict the $\mathrm{EC} 50_{\mathrm{As}(\mathrm{V})}$ and $\mathrm{EC} 10_{\mathrm{As}(\mathrm{V})}$ as water quality criteria for 0 . mossambicus. Fig. $6 \mathrm{~A}$ and $\mathrm{B}$ shows that the predicted $\mathrm{EC} 5 \mathrm{As}_{\mathrm{As}(\mathrm{V})}$ in
Taihsi and Peimen ranged from 5 to $2.2 \mathrm{nM}$ and from 170 to $100 \mathrm{nM}$, respectively, whereas the predicted $\mathrm{EC} 10_{\mathrm{As}(\mathrm{V})}$ ranged from 2.7 to $1.1 \mathrm{nM}$ and from 101.8 to $41.3 \mathrm{nM}$, respectively. Predictions indicate that the growth toxicity of 0 . mossambicus in Taihsi tilapia farm is more sensitive than that in Peimen.

We employed Eq. (4) associated with a BLM and DAM-based safety function, $S(t)$ [Eq. (5)], to predict the site-specific growth trajectories of tilapia from birth to natural death under different exposure scenarios (ranging from $0,1,2$ and $4 \mu \mathrm{g} \mathrm{mL}^{-1}$ ). We assumed that the chemical stresses would not shorten the life-span of tilapia (about 4000 d). Fig. $6 C$ and D demonstrates the simulations of time course of body weight of tilapia subject to selected waterborne As $\left(0,1,2,4 \mu \mathrm{gL}^{-1}\right)$ concentrations with water quality criteria of EC50 and EC10, respectively. Results show that the concentrationspecific predicted EC50 maximum biomasses of tilapia in Peimen are 1065.3, 1052.9, 1052.2, and $1027.2 \mathrm{~g}$, respectively; whereas for the groups in Taihsi are 1065.3, 992.4, 934.7, and $819.7 \mathrm{~g}$, respectively, varied with As concentrations of $0,1,2$, and $4 \mu \mathrm{g} \mathrm{mL}^{-1}$ (Fig. 6C and D). The concentration-specific EC10 maximum biomasses of tilapia range from 1065.3 to $1038.8 \mathrm{~g}$ in Peimen and 1065.3 to $1042.6 \mathrm{~g}$ in Taihsi, respectively.

The site-specific risk of growth inhibition in the criteria of $10 \%$ and $50 \%$ effects is calculated as $1-S(t)$ (Fig. 1 and Table 2). Fig. $6 \mathrm{E}$ and $\mathrm{F}$ illustrates the probability of growth inhibition in different As concentrations. The growth inhibition risks in both sites show exponential increase with the concentration of As. In the criteria of $10 \%$ 


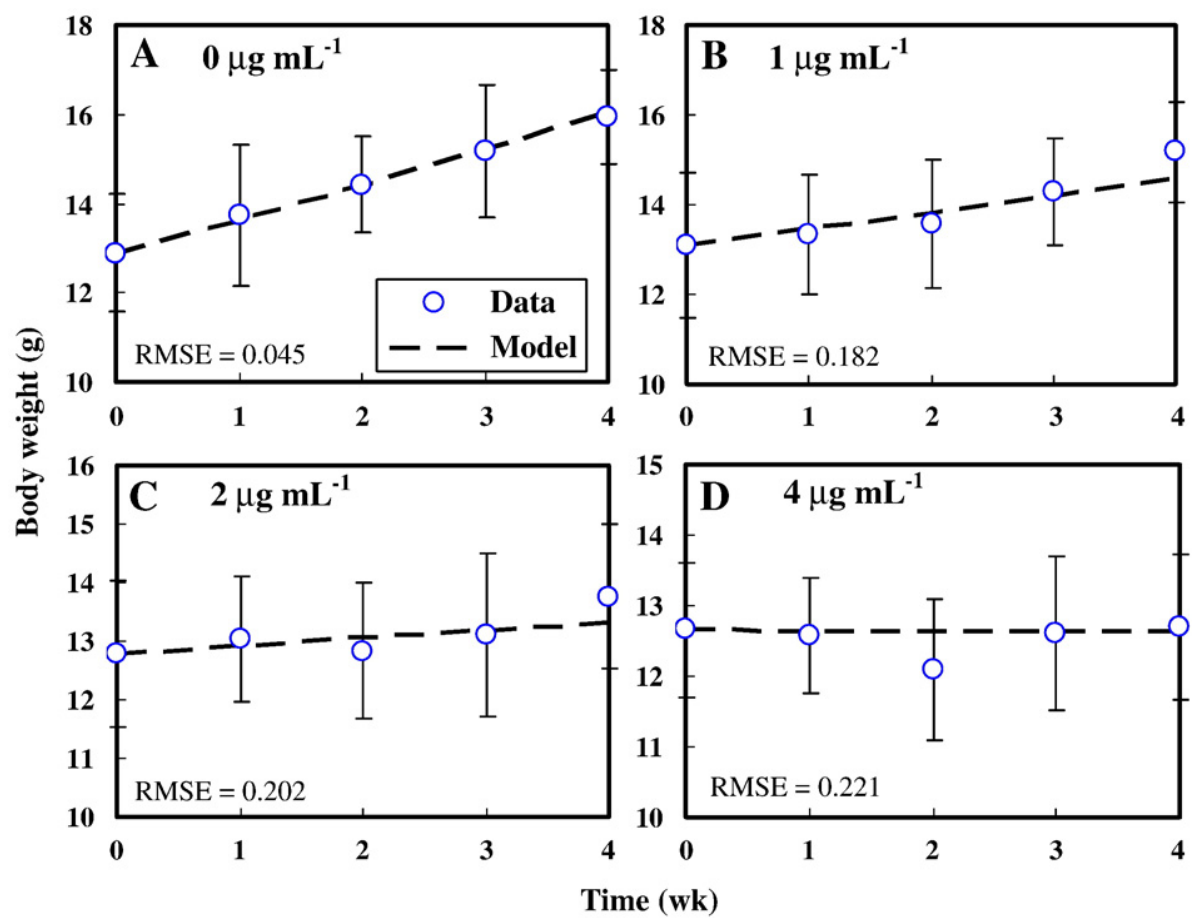

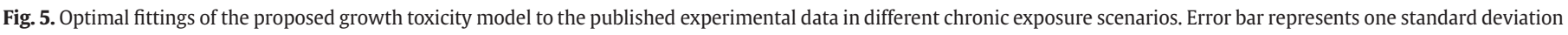
from the mean.

effect, the maximum risk of individual growth inhibition approaching 1, i.e., the fish biomass does not increase at all, occurring in $93 \mu \mathrm{g} \mathrm{mL}-1$ (15.68 nM) in Taihsi and in $10,000 \mu \mathrm{g} \mathrm{mL}^{-1}$ (627.96 $\mathrm{nM}$ ) in Peimen, respectively. Similarly, the maximum risk in $50 \%$ effect approaching 0.97 occurred in $200 \mu \mathrm{gL}^{-1}(35.08 \mathrm{nM})$ in Taihsi and in $20,000 \mu \mathrm{g} \mathrm{mL}^{-1}(3508.06 \mathrm{nM})$ in Peimen, respectively. Results indicate that the effect of ion competition on the As bioavailability and their ecotoxicological effects on tilapia are more obvious in Taihsi comparing with that in Peimen. We thus suggested that the proposed bioavailability- and mode of action-based framework can be used to capture the biological response and regulation of tilapia to As exposures and is applicable for a site-specific and long-term ecotoxicological risk assessment.

\section{Discussion}

\subsection{Toxicodynamics and mode of toxic action}

We developed a bioavailability- and mode of action-based algorithm to predict the site-specific toxic effects of As on organisms in their entire life span. This approach facilitates the using of shortterm lab data to extrapolating the long-term field prediction. The proposed models were validated and were performed by assuming that the essential toxicokinetic parameters, i.e., $k_{1}, k_{2}$ and bioconcentration factor are constant between acute and chronic schemes, and the mode of action is identical through out the whole life span. However, this might be controversial and would cause uncertainty in long-term and field predictions. Identical toxicokinetic parameters and MOA imply that there will be similar mechanisms governing the short- and long-term effects because the model parameters have to be analyzed in view of the biological assumptions of the models and the fit of model is strongly affected by the input toxicokinetic parameters. Therefore, the uncertainties in the input values of $k_{1}, k_{2}$ and bioconcentration factor affect the validation of the models.

Several studies revealed that the toxicological changes of metals in fish are determined upon exposure concentration and duration as well as other biological regulations. McGeer et al. (2003) showed that an inverse relationship exists between BCF and exposure concentration. Liao et al. (2003) also revealed that the field tilapia featured with higher As accumulation ability (bioconcentration factor $=143-421$ ) than those adopted in their 7-d lab bioaccumulation assays (biocon- centration factor $=1.04-4.19)$, in which the lab group suffered with about 30 times higher waterborne As concentrations than the field group. The relatively higher value of bioconcentration factor obtained from lower chemical exposures may result from the acclimation or adaptation of organism to chemicals.

Physiological acclimation and/or genetic adaptation to metals in natural environment and laboratory are well documented for organisms (Muyssen and Janssen, 2005). Generally, such an acclimation treatment might render the organisms less sensitive to metal toxicity and induces the transition of the mode of toxic action. Forrester et al. (2003) also pointed out that chronic exposures may induce physiological acclimation or genetic adaptation to a local contaminant regime. This would cause the limitations for assessing the long-term effects by using the short-term acute toxicity data. It seems reasonable that organisms might somehow become weakened or acclimatized after enduring long-term chemical loading, and nonspecific, initially sublethal effects might worsen or mitigate with

Table 3

Site-specific ion activities of key water chemistry features calculated by WHAM from official published measured ion free concentrations for tilapia farms in Taihsi and Peimen.

\begin{tabular}{lllll}
\hline $\begin{array}{l}\text { Water ionic } \\
\text { activities } \\
(\mathrm{mM})\end{array}$ & Taihsi $^{\mathrm{a}}$ & & Peimen $^{\mathrm{a}}$ & \\
\hline $\mathrm{Ca}^{2+}$ & $0.30 \pm 0.07^{\mathrm{b}}$ & $\mathrm{LN}(0.29,1.27)^{\mathrm{c}}$ & $1.31 \pm 0.27^{\mathrm{b}}$ & $\mathrm{LN}(1.29,1.22)^{\mathrm{c}}$ \\
$\mathrm{Mg}^{2+}$ & $0.21 \pm 0.03$ & $\mathrm{LN}(0.21,1.17)$ & $11.45 \pm 1.58$ & $\mathrm{LN}(11.37,1.15)$ \\
$\mathrm{Na}^{+}$ & $3.85 \pm 0.57$ & $\mathrm{LN}(3.81,1.16)$ & $312.56 \pm 55.42$ & $\mathrm{LN}(307.12,1.19)$ \\
$\mathrm{Cl}^{-}$ & $2.63 \pm 0.67$ & $\mathrm{LN}(2.54,1.29)$ & $461.95 \pm 72.15$ & $\mathrm{LN}(457.03,1.17)$ \\
$\mathrm{SO}_{4}^{2-}$ & $0.38 \pm 0.08$ & $\mathrm{LN}(0.37,1.24)$ & $6.03 \pm 1.00$ & $\mathrm{LN}(5.95,1.18)$ \\
$\mathrm{H}^{+}$ & $6.88 \times 10^{-5} \pm \mathrm{LN}\left(6.38 \times 10^{-5}, 1.47\right)$ & $1.09 \times 10^{-4} \pm$ & $\mathrm{LN}\left(1.04 \times 10^{-4}, 1.37\right)$ \\
& $2.77 \times 10^{-5}$ & $3.44 \times 10^{-5}$ & \\
$\mathrm{As}^{5+}$ & $1.59 \times 10^{-8} \pm \mathrm{LN}\left(1.58 \times 10^{-8}, 1.09\right)$ & $1.23 \times 10^{-9} \pm$ & $\mathrm{LN}\left(1.15 \times 10^{-9}, 1.46\right)$ \\
& $1.32 \times 10^{-9}$ & & $4.85 \times 10^{-10}$ & \\
\hline
\end{tabular}

a Adopted from the Taiwan Environmental Protection Administration (http:// wqshow.epa.gov.tw)

b Mean \pm SD.

c Lognormal distribution with a geometric mean and a geometric standard deviation. 


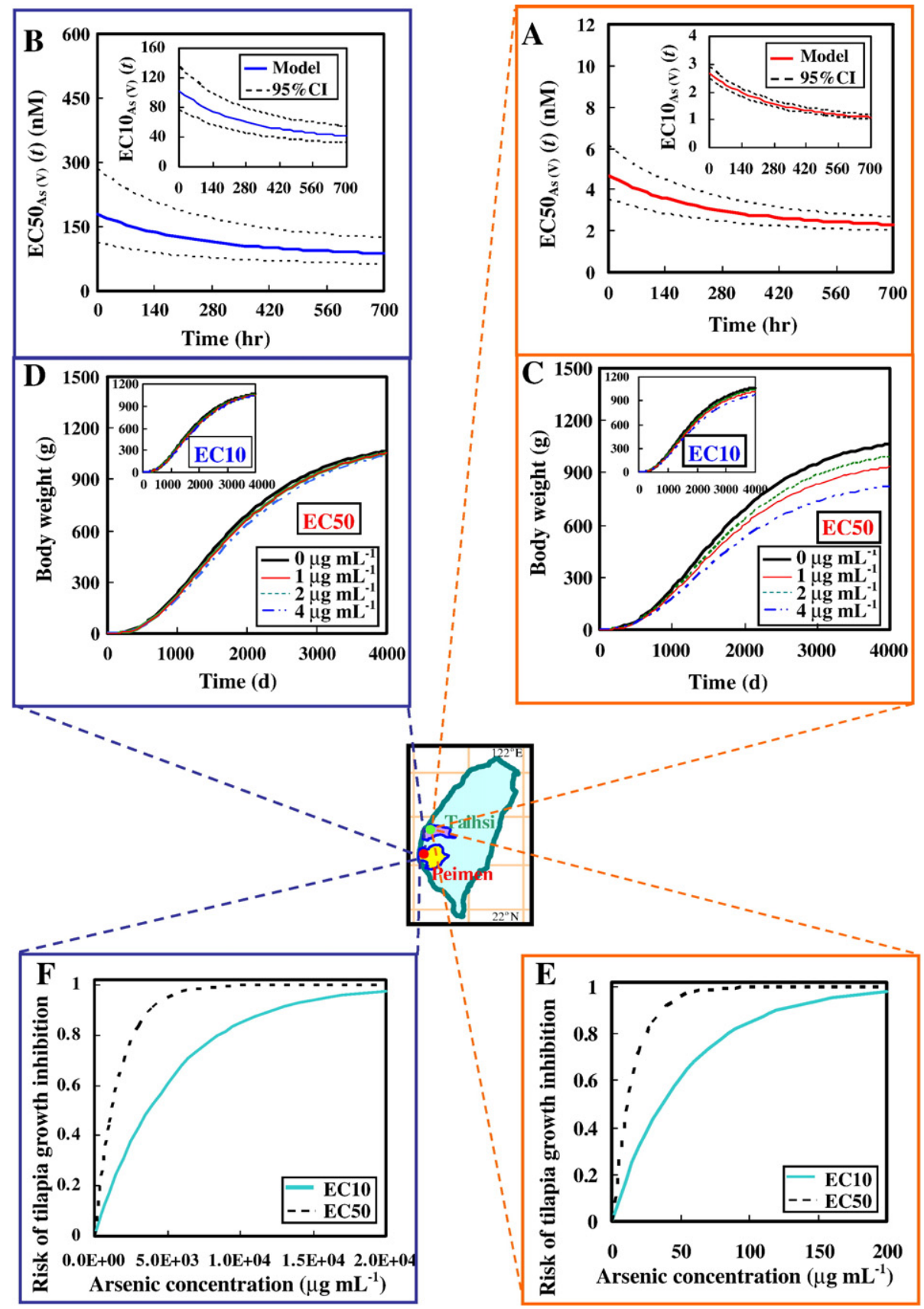

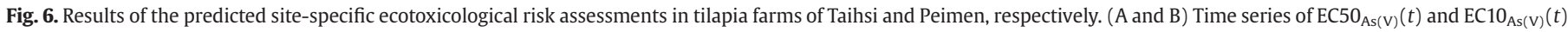

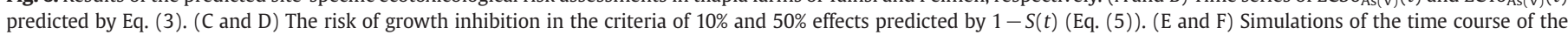
biomass of tilapia in the entire life span in different waterborne As concentration with the water quality criteria of EC50 and EC10.

time. If the acclimation/adaptation occurs, resulting in the changes of toxicokinetic processes and mode of toxic action. The proposed methodology might be inadequate for a longer term risk assessment.

\subsection{Life cycle assessment}

A life-cycle toxicity test provides vital knowledge for chemical risk assessment in population and community levels. Although providing a wealth of information, these tests are usually extremely hard to analyze, because testing life-cycle consequences is too complicated and too expensive for routine applications. Consequently, short-term testing with selected life cycle is used as a surrogate (Jager et al., 2004). Here we adopted a 28-d growth bioassay data of sub-adult tilapia to predict growth trajectories of tilapia in whole life span. The merit of West growth model can elucidate the growth trajectories of organism over the entire life cycle solely based upon the growth information in a selected time interval. However, the difference in chemical sensitivity between life stages should be further considered if the life-cycle-specific toxic response is observed.

Some studies assume that chemicals affect organisms by impairment of those life-cycle variables that are most sensitive to these toxicants. For example, to assess the impact of contaminants on organisms, a general toxicological approach is to quantify the response of juvenile, because this is often known to be the most sensitive life cycle variable with respect to chemical stress (DeLonay et al., 1993; Kammenga et al., 1996). To explicitly assess the chemical effects for a longer-term aspect, multi-life stage toxicity bioassays should be involved in the process of toxic texts to explicitly assess the metal toxicity to the entire life cycle of organisms. 


\subsection{Bioregulation and chemical metabolism}

Evaluating chemical toxicity on the basis of internal effect concentration could automatically account for differences in bioavailability and exposure condition. The BLM suggests that the fraction of the biotic ligand sites occupied by metal ions $\left(\mathrm{M}^{+}\right), f_{\mathrm{MBL}}$, provides an approximation of the chemical dose at target sites than the concentration in the exposure medium alone. Our approach well predicts the relationship between internal effect concentration and duration (i.e., $\left.f_{\mathrm{As}(\mathrm{V})}^{50 \%}(t)\right)$ and distinguished the quantitative difference between acute and chronic exposure conditions by linking the knowledge of toxicokinetic processes. Although there is little evidence of active regulation of internal As concentrations by fish, it is clear from the inverse relationship between bioconcentration factor and exposure concentration that some physiological control over As accumulation can be achieved (Liao et al., 2007). De Schamphelaere and Janssen (2004) and Heijerick et al. (2005) revealed that values of acute $f_{\mathrm{MBL}}^{50 \%}$ are larger than the chronic values, supporting our predictions for the $f_{\mathrm{As}(\mathrm{V})}^{50 \%}(t)$.

Redeker and Blust (2004) indicated that aquatic organisms can regulate the internal metals such as copper or zinc within a narrow concentration window by active regulation of toxicokinetic process (i.e., biouptake and/ or elimination). This means that the internal effect concentration is independent of the exposure condition. However, the accumulated metal does not necessarily result in metal toxicity. Metals are distributed between various organs that process metals in different ways such as the hepatopancreas, the nephridia, or the muscle tissues.

Within these tissue compartments, metals would be bound by ligands that form kinetically labile and more stabile complexes, some of which remain biologically reactive, whereas others do not play a role in active metabolism and can be considered as internal metal stores or sinks (Vijver et al., 2004). This means that parts of the metals present in an organ or specific tissues within an organism does not necessarily contribute to toxicity, suggesting that the concept of a critical receptor occupied only holds when the formation of stable and inert complexes is limited and all of the metal present in a certain tissue compartment can be considered to be biologically reactive or that the reactive pool is a constant proportion of the total metal concentration (Redeker and Blust, 2004). We suggested that the issue of determination and assessment of extend of chemical metabolism and the toxicity of metabolites should be addressed in the future study.

\subsection{Application of BLM in field risk assessment}

Examining the individual effect of competing ions, $\mathrm{H}^{+}$and natural organic matter on the target metal toxicity is the first step requirement for developing a BLM. Although there is no specific experiment-based BLM and model parameters have been developed for selected As exposures, our proposed general models seemly predict the temporal change of As toxicity data well in both acute and chronic scenario (Fig. 3A and B). The major difference between our acute and chronic BLMs is only distinguished by the change in $f_{\mathrm{As}(\mathrm{V})}^{50 \%}(t)$ and the affinity constant of metal and cations to the receptor (i.e., $K_{C i B L}$ and $K_{\mathrm{AsBL}}$ ), this is a simplified approach to develop the model if the inherent mechanisms that account for both the short- and long-term effects are similar (Heijerick et al., 2005). However, some literatures reveal that the importance of cation competitive interaction obviously changes upon the exposures, therefore, the chronic BLM cannot simply be derived from the acute model (De Schamphelaere and Janssen, 2004; Schwartz and Vigneault, 2007). We suggest that future research or further revision of the As BLM should focus on validation and better understanding of the key processes that determine and change As toxicity.

Most of our calculated external effect concentrations (i.e., $\mathrm{LC} \mathrm{AO}_{\mathrm{As}(\mathrm{V})}$ and $\left.\mathrm{EC} \mathrm{O}_{\mathrm{As}(\mathrm{V})}\right)$ were estimated from bioassays which were conducted in deionic water (i.e., all cation competing activities can be ignored) and we do not involved the consideration about dissolved organic matter complexation of As in the proposed models. This might lead to the misestimating of essential model parameters and thus weaken the reliability of the site-specific risk assessment. Effects of dissolved organic matter on metal bioavailability are particularly essential in field risk assessment, because dissolved organic matter is quantitatively large in field habitats and their compositions are usually too complex to analyze. This is why the dissolved organic matter has not been involved in the BLM. The potential of the proposed algorithm for assessing chronic As toxicity in field sites will depend upon the accuracy of the modeled interactions between metal ions and dissolved organic matter. A good understanding of the speciation processes and binding capacity of dissolved organic matter to As will be critical for obtaining reliable in-situ predictions.

\section{References}

Chen CM, Yu SC, Liu MC. Use of Japanese medaka (Oryzia latipes) and tilapia (Oreochromis mossambicus) in toxicity tests on different industrial effluents in Taiwan. Arch Environ Contam Toxicol 2001;40:363-70.

Chen BC, Chen WY, Liao CM, in press. A biotic ligand model-based toxicodynamic approach to predict arsenic toxicity to tilapia gills in cultural pond. Ecotoxicol. doi:10.1007/s 10646-008-0292-z.

DeLonay AJ, Little EE, Woodward DF, Brumbaugh WG, Farag AM, Rabeni CF. Sensitivity of early-life-stage golden trout to low $\mathrm{pH}$ and elevated aluminium. Environ Toxicol Chem 1993;12:1223-32.

De Schamphelaere KAC, Janssen CR. Development and field validation of a biotic ligand model predicting chronic copper toxicity to Daphnia magna. Environ Toxicol Chem 2004;23:1365-75.

Fergusion JF, Gavis J. A review of the arsenic cycle in natural waters. Wat Res 1972;6: 1259-74.

Forrester GE, Fredericks BI, Gerdeman D, Evans B, Steele MA, Zayed K, et al. Growth of estuarine fish is associated with the combined concentration of sediment contaminants and shows no adaptation or acclimation to past conditions. Mar Environ Res 2003;56:423-42

Heijerick DG, De Schamphelaere KAC, Janssen CR. Predicting acute zinc toxicity for Daphnia magna as a function of key water chemistry characteristics: development and validation of a biotic ligand model. Environ Toxicol Chem 2002;21:1309-15.

Heijerick DG, De Schamphelaere KAC, Van Sprang PA, Janssen CR. Development of a chronic zinc biotic ligand model for Daphnia magna. Ecotox Environ Safe 2005;62:1-10.

Jager T, Crommentuijn T, Van Gestel CAM, Kooijman SALM. Simultaneous modeling of multiple end points in life-cycle toxicity tests. Environ Sci Technol 2004;38:2894-900.

Kammenga JE, Busschers M, Van Straalen NM, Jepson PC, Bakker J. Stress induced fitness reduction is not determined by the most sensitive life-cycle trait. Funct Ecol 1996;10: 106-11.

Kooijman SALM, Bedaux JJM. The analysis of aquatic toxicity data. Amsterdam, The Netherlands: VU University press; 1996.

Lee JH, Peter FL, Koh CH. Prediction of time-dependent PAH toxicity in Hyalella azteca using a damage assessment model. Environ Sci Technol 2002;36:3131-8.

Legierse KCHM, Verhaar HJM, De Bruijn JHM, Herman JLM. Analysis of the timedependent acute aquatic toxicity of organophosphorus pesticides: the critical target occupation model. Environ Sci Technol 1999;33:917-25.

Liao CM, Chen BC, Singh S, Lin MC, Liu CW, Han BC. Acute toxicity and bioaccumulation of arsenic in tilapia (Oreochromis mossambicus) from a blackfoot disease area in Taiwan. Environ Toxicol 2003;18:252-9.

Liao CM, Tsai JW, Ling MP, Liang HM, Chou YH, Yang PT. Organ-specific toxicokinetics and dose-response of arsenic in tilapia Oreochromis mossambicus. Arch Environ Contam Toxicol 2004;47:502-10.

Liao CM, Jou LJ, Lin CM, Chiang KC, Yeh CH, Chou BYH. Predicting acute copper toxicity to valve closure behavior in the freshwater clam Corbicus fluminea supports the biotic ligand model. Environ Toxicol 2007;22:295-307.

McCarty LS, Mackay D. Enhancing ecotoxicological modeling and assessment. Environ Sci Technol 1993;27:1719-28.

McGeer JC, Brix KV, Skeaff JM, DeForest DK, Brigham SI, Adams WJ, et al. Inverse relationship between bioconcentration factor and exposure concentration for metals: implications for hazard assessment of metals in the aquatic environment. Environ Toxicol Chem 2003;22:1017-37.

Meyer JS, Santore RC, Bobbit JP, Debrey LD, Boese CJ, Paquin PR, et al. Binding of nickel and copper to fish gills predicts toxicity when water hardness varies but free-ion activity does not. Envrion Sci Technol 1999;33:913-6.

Muyssen BTA, Janssen CR. Importance of acclimation to environmentally relevant zinc concentrations on the sensitivity of Daphnia magna toward zinc. Environ Toxicol Chem 2005;24:895-901.

Nisbet RM, Muller EB, Lika K, Kooijman SALM. From molecules to ecosystem through dynamic energy budget models. J Anim Ecol 2000;69:913-26.

Niyogi S, Wood CM. Biotic ligand model, a flexible tool for developing site-specific water quality guidelines for metals. Environ Sci Technol 2004;38:6177-92.

Pagenkopf GK. Gill surface interaction model for trace metal toxicity to fish: role of complexation, pH and water hardness. Environ Sci Technol 1983;17:342-7.

Redeker ES, Blust R. Accumulation and toxicity of cadmium in the aquatic oligochaete Tubifex tubifex: a kinetic modeling approach. Environ Sci Technol 2004;38:537-43.

Schwartz ML, Vigneault B. Development and validation of a chronic copper biotic ligand model for Ceriodaphnia dubia. Aquat Toxicol 2007;84:247-54. 
Singh S. A physiologically based pharmacokinetic and pharmacodynamic model for arsenic accumulation in aquacultural fish from blackfoot disease area in Taiwan. Unpublished PhD dissertation. National Taiwan University; 2001.

Tsai JW, Liao CM. A dose-based modeling approach for accumulation and toxicity of arsenic in tilapia Oreochromis mossambicus. Environ Toxicol 2006a;21:8-21.

Tsai JW, Liao CM. Mode of action and growth toxicity of arsenic to tilapia Oreochromis mossambicus can be determined bioenergetically. Arch Environ Contam Toxicol 2006b;50:144-52.

Tsai JW, Liao CM, Liao VHC. A biologically based damage assessment model to enhance aqua cultural water quality management. Aquaculture 2006;251:280-94.

USEPA (United States Environmental Protection Agency). National recommended water quality criteria; 2002. EPA-822-R-02-047. Website: http://www.epa.gov/ost/pc/ revcom.pdf.
Vijver MG, Van Gestel CAM, Lanno RP, Van Straalen NM, Peijnenburg WJGM. Internal metal sequestration and its ecotoxicological relevance: a review. Environ Sci Techno 2004;38:4705-12.

Wang SW, Liu CW, Jang CS. Factor responsible for high arsenic concentrations in two groundwater catchments in Taiwan. Appl Geochem 2007;22:460-76.

West GB, Brown JH. Life's universal scaling laws. Phys Today 2004;57:36-42.

West GB, Brown JH, Enquist BJ. A general model for ontogenetic growth. Nature 2001;413: 628-31. 